\title{
Family Physicians Improve Patient Health Care Quality and Outcomes
}

\author{
Marjorie A. Bowman, MD, MPA, and Anne Victoria Neale, PhD, MPH
}

This issue exemplifies family physicians' ability to provide great care and to continuously improve. For example, beyond other specialty care, the care provided by family physicians is associated with improved melanoma diagnosis and outcomes and improved preventive services for those with a history of breast cancer. Electronic health records are providing new avenues to both assess outcomes and influence care. However, to truly reward quality care, simplistic and readily measurable items such as laboratory results or assessment of the provision of preventive services must be adjusted for risk. Health insurance influences classic preventive care services more than personal health behaviors. The care provided at federally qualified health centers throughout the nation is highly appreciated by the people they serve and is not plagued by the types of disparities in other settings. ( $\mathrm{J}$ Am Board Fam Med 2013; 26:617-619.)

Maly et $\mathrm{al}^{1}$ show the positive impact of family physicians on recommended preventive services in the follow-up care of underserved female breast cancer survivors. The disparity between specialities was dramatic for colonoscopy in particular, where only a quarter of patients seeing only surgeons/ cancer specialists for follow-up received the recommended screening.

Related to another cancer-melanoma-Roetzheim et $\mathrm{al}^{2}$ showed that visiting a family physician compared with only a dermatologist before the diagnosis of melanoma was associated with a diagnosis of more thin melanomas and possibly a lower rate of mortality. To improve the accuracy of detection of skin cancers, Eide et $\mathrm{al}^{3}$ tested an intriguing intervention using a readily available, 1- to 2-hour, interactive web-based course. In addition to evaluations after the course, this study considered referrals to dermatology before and after the course and diagnoses after the course. Most of the providers had trained in internal medicine. The evaluations immediately and after 6 months found improved scores, and the later practice patterns found fewer referrals to dermatology but no obvious change in the rate of diagnosis of skin cancers. The physicians reporting no past dermatology training had the greatest improvement.

Conflict of interest: The authors are editors of the $7 A B F M$.

\section{Effects of Insurance on Preventive Services and Health Behaviors}

Jerant et $\mathrm{al}^{4}$ reported that patients who newly obtained health insurance after being uninsured clearly receive more recommended preventive care that are based on the health system (eg, Papanicolaou tests, mammograms, and immunizations); the opposite is also true: losing insurance decreases these services. Yet patients' personal health behaviors did not improve or worsen with changes in health insurance. Unfortunately, this questions the ability of the health care system to either recognize negative patient behaviors, assist patients in changing them, or both. Perhaps follow-up longer than 1 year would change these outcomes since behavior changes often take repeated efforts over multiple years.

\section{Risk Adjustment of Improvement Assessment of Quality by Family Physician Offices}

Two articles in this issue are quite important in our era when more of the reimbursement to family physicians is based on readily available, measurable numbers that are deemed to reflect quality of care. However, risk adjustment changes apparent blood pressure and cholesterol control ${ }^{5}$ as well as the provision of glycohemoglobin and microalbumin testing, influenza immunizations, and lipid screening for patients with diabetes. ${ }^{6}$ Of course, family physicians have long argued the need for risk ad- 
justment; we can help all patients at least some, but our ability to help all patients reach goals-no matter who the patient is, what their living circumstances are, and what the goals are-is unrealistic. These findings mean quality reimbursement incentives from insurance companies must go beyond mere quick checks of the patient's absolute laboratory test values to pay out "quality" incentives. Other appropriate factors must be considered. Both teams of authors completed their work with information from electronic health records, proving that this is possible across different electronic medical records, across practices, and across the country. Neither method was simple, and the teams considered different risk adjustment, so more work will need done.

\section{Office Provision of Health Services}

Lebrun-Harris et $\mathrm{al}^{7}$ provide encouraging evidence that patients report excellent satisfaction at Federally Qualified Community Health Centers, based on a sample of 4562 patients representing 16 million patient nation-wide). Further, these experiences indicated few racial, ethnic, and insurance related disparities, far different from what is reported in some other settings. Access to care seems to be an important factor in health disparities.

In patients with a usual source of care, those who have better access to their primary care site after hours, and who either did speak the same language as their primary care clinician or received translator support, are less likely to seek non-emergent care in emergency rooms. ${ }^{8}$ Neither of these should be unexpected, but continue to reinforce the importance of physician-patient communication in the office and the short geographic distances to primary care.

Lane et $\mathrm{al}^{9}$ took a novel approach and revealed how students and university support can also assist practices to attain PCMH recognition.

Many family medicine teaching programs have experienced the benefits of the presence of various types of learners - such as physician assistant, nursing, pharmacy or psychology students - on teaching and patient care. McKee et $\mathrm{al}^{10}$ initiated a program with a different type of student - acupuncture students - and showed patient-reported improvement in chronic pain in clinics for underserved patients. Good idea. Good outcome.

Gagnon et $\mathrm{al}^{11}$ demonstrated that a seven-item insomnia questionnaire with good test characteris- tics was easy to use in general practice offices in Canada. In another paper from our Canadian colleagues, Paquette-Warren et $\mathrm{al}^{12}$ showed how a diabetes quality improvement project was associated with improved patient measures. Their physicians describe the factors that felt most helped create the positive outcomes.

Ruffin et $\mathrm{al}^{13}$ found that provider characteristics were significant determinants of ordering HPV testing with cytology Papanicolaou tests - women physicians or academic physicians and residents were more likely, and NP/PA's were particularly unlikely, to order the HPV testing. One office site had a different method of completing the forms (staff as compared with provider), leading to HPV not being ordered routinely. National guidelines are that concurrent cytology and HPV testing for low risk women age 30-65 years means that the screening can be every 5 years rather than every 3 years. An unresolved question is whether the concurrent HPV testing was actually associated with longer times to rescreening, ie, the every 5 versus the 3 years. Further, patients are getting different care based on the characteristics of their provider why?

A family medicine prenatal group visit program for a group of patients with limited English proficiency (in this case, Japanese women) is feasible, as noted by Little et al. ${ }^{14}$ Husbands and children were included and attendance and satisfaction were high.

\section{Care of Patients With Specific Health Issues}

Van Assen et $\mathrm{al}^{15}$ provide a wonderfully clinically relevant article on how to detect an underdiagnosed cause of chronic abdominal pain: anterior cutaneous nerve entrapment syndrome (ACNES). Over the years, I (M.A.B.) have encountered several of these; the easy intervention and excellent outcomes are quite rewarding for both doctor and patient. The authors sought out patients with a diagnosis of functional abdominal pain and used an ACNES questionnaire to identify the patients most likely to have the syndrome. One-third who met the cutoff score had ACNES $3.6 \%$ of those with functional abdominal pain) and could be treated or reassured. Uncommon, but treatable-let's find and treat them!

Kupetsky et $\mathrm{al}^{16}$ provide a useful review of diagnosing and treating psoriasis for primary care clinicians. Wahlert and Fiester ${ }^{17}$ caution us that, de- 
spite gains, there are still unclear areas for lesbian, gay, bisexual, and transgender patients related to decision making regarding medical care.

O'Grady et $\mathrm{al}^{18}$ found that automated printed clinical reminders did not affect weight loss in overweight/obese patients in their setting. Herbitter et $\mathrm{al}^{19}$ revealed that most academic family physicians have experience treating failure of early pregnancy, often with medications, but a minority have provided abortions during early pregnancy.

Veghari et $\mathrm{al}^{20}$ report on the high but decreasing consumption of hydrogenated oils, which are cheaper than other edible oils, in Iran. Consumption of hydrogenated oils is a world-wide phenomena, often more so than we appreciate; they often are found in highly manufactured/prepared foods in the United States, such as store-bought cookies and muffins.

Glassberg et $\mathrm{al}^{21}$ literally show us a complication that needs to be recognized when it occurs but that could easily be overlooked: a fractured catheter.

\section{References}

1. Maly RC, Liu Y, Diamant AL, Thind A. The impact of primary care physicians on follow-up care of underserved breast cancer survivors. J Am Board Fam Med 2013;26:628-36.

2. Roetzheim RG, Lee J-H, Ferrante JM, et al. The influence of dermatologist and primary care physician visits on melanoma outcomes among medicare beneficiaries. J Am Board Fam Med 2013;26:637-47.

3. Eide MJ, Asgari MM, Fletcher SW, et al. Effects on skills and practice from a web-based skin cancer course for primary care providers. J Am Board Fam Med 2013;26:648-57.

4. Jerant A, Fiscella K, Tancredi DJ, Franks P. Health insurance is associated with preventive care but not personal health behaviors. J Am Board Fam Med 2013;26:759-67.

5. Hammermeister K, Bronsert M, Henderson WG, et al. Risk-Adjusted Comparison of Blood Pressure and Low-Density Lipoprotein (LDL) Noncontrol in Primary Care Offices. J Am Board Fam Med 2013; 26:658-68.

6. Bailey SR, O'Malley JP, Gold R, Heintzman J, Likumahuwa S, DeVoe JE. Diabetes care quality is highly correlated with patient panel characteristics. J Am Board Fam Med 2013;26:669-79.

7. Shi L, Lebrun-Harris LA, Parasuraman SR, Zhu J, Ngo-Metzger Q. The quality of primary care expe- rienced by health center patients. J Am Board Fam Med 2013;26:768-77.

8. Villani J, Mortensen K. Nonemergent emergency department use among patients with a usual source of care. J Am Board Fam Med 2013;26:680-91.

9. Lane SJ, Watkins RW. Helping primary care practices attain patient-centered medical home $(\mathrm{PCMH})$ recognition through collaboration with a university. J Am Board Fam Med 2013;26:784-6.

10. McKee MD, Kligler B, Fletcher J, et al. Outcomes of acupuncture for chronic pain in urban primary care. J Am Board Fam Med 2013;26:692-700.

11. Gagnon C, Bélanger L, Ivers H, Morin CM. Validation of the Insomnia Severity Index in primary care. J Am Board Fam Med 2013;26:701-10.

12. Harris S, Paquette-Warren J, Roberts S, et al. Results of a mixed-methods evaluation of partnerships for health: a quality improvement initiative for diabetes care. J Am Board Fam Med 2013;26:711-9.

13. de la Cruz MD, Young AP, Ruffin IV MT. Human papillomavirus (HPV) testing for normal cervical cytology in low-risk women age 30-65 years by family physicians. J Am Board Fam Med 2013;26: $720-7$.

14. Little SH, Motohara S, Miyazaki K, Arato N, Fetters MD. Prenatal group visit program for a population with limited English proficiency. J Am Board Fam Med 2013;26:728-37.

15. van Assen T, de Jager-Kievit JWAJ, Scheltinga MR, Roumen RMH. Chronic abdominal wall pain misdiagnosed as functional abdominal pain. J Am Board Fam Med 2013;26:738-44.

16. Kupetsky EA, Keller M. Psoriasis vulgaris: an evidence-based guide for primary care. J Am Board Fam Med 2013;26:787-801.

17. Wahlert L, Fiester A. A false sense of security: lesbian, gay, bisexual, and transgender (LGBT) surrogate health care decision-making rights. J Am Board Fam Med 2013;26:802-4.

18. O'Grady JS, Thacher TD, Chaudhry R. The effect of an automated clinical reminder on weight loss in primary care. J Am Board Fam Med 2013;26:745-50.

19. Herbitter C, Bennett A, Schubert FD, Bennett IM, Gold M. Management of early pregnancy failure and induced abortion by family medicine educators. J Am Board Fam Med 2013;26:751-8.

20. Veghari G, Sedaghat M, Maghsodlo S, et al. Fiveyear trend in hydrogenated vegetable oil consumption among northern Iranian families. J Am Board Fam Med 2013;26:778-83.

21. Glassberg E, Lending G, Abbou B, Lipsky AM. Something's missing: peripheral intravenous catheter fracture. J Am Board Fam Med 2013;26:805-6. 